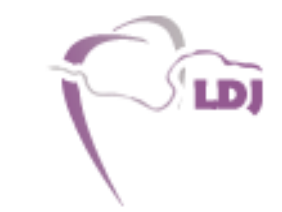

\title{
LASER WELDING OF DENTAL ALLOYS: A SYSTEMATIC OVERVIEW
}

Shanti Varghese1, Vinaya Bhat2, Suja Joseph³,

1) Department of Prosthodontics, Noorul Islam College of Dental Sciences, Kerala University, India.

2) Department of Prosthodontics, A.B Shetty Memorial Institute of Dental Sciences, Nitte University, Mangalore, India

3) Deprtment of Prosthodontics, Pushpagiri Dental College, Peruthurithi, Thiruvalla,Kerala, India

\section{ARTICLE INFORMATION:}

\section{Article History:}

Received: 24 December, 2013

Accepted in revised form: 15 March

2014

Published: 8 July, 2014

Corresponding author:

Shanti Varghese,

E-mail: shantivrghs@yahoo.com

\section{Keyword:}

laser welding, welding dental alloys, welding parameters

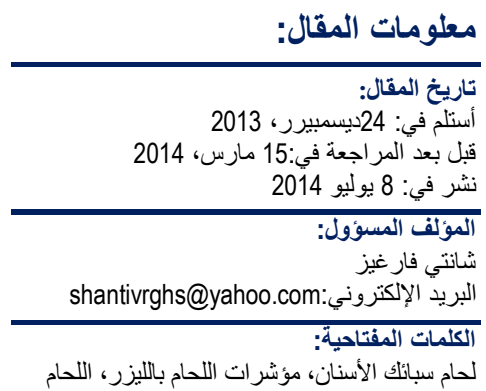

\begin{abstract}
:
Aim: The objective of this article is to review information on laser welding of dental alloys. Its rationale, design, advantages, and disadvantages have been reviewed and compared with the conventional techniques of joining dental alloys. Its effects on the commonly used dental alloys and its associated welding defects have also been discussed.

Materials and Methods: A broad search of the published literature was performed using Medline and pub med from 1960 to 2012. The key words used for the search were 'laser welding', 'dental alloys', 'laser parameters', 'welding principle' and 'welding procedure'. It was observed that much of the research work was done from the year 2000 onwards. A hand search of textbooks, relevant articles, and manufacturers' literature was also conducted.

Results: Within the limitations of the information obtained and systematically reviewed, it can be inferred that laser beam welding definitely outwits the conventional procedures of joining dental alloys. High precision, accuracy and productivity, reduced distortion, high mechanical strength of the weld joint, corrosion resistant weld joint are a few advantages of laser beam welding technique. The main drawback of laser welding includes its high investment, operating and maintenance costs. To overcome the minor drawbacks of laser welding, TIG welding has been introduced. It involves reduced investment costs, very compact dimensions, low weight, maintenance free and low operating costs.

Conclusion: A number of techniques are available for joining dental alloys; each having its own pros and cons. Laser welding still remains the recommended technique due to its precision and accuracy. Continuing research and development are resulting in newer technologies that can overcome the drawbacks of previous techniques. This will provide clinicians and technicians more options in the realm of adequate training and operator expertise.
\end{abstract}

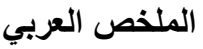

اللحام الليزري لسبائك الأسنان: مراجعة منهجية

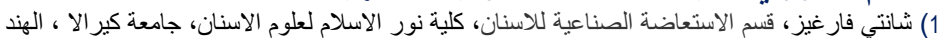

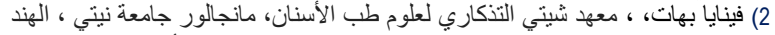

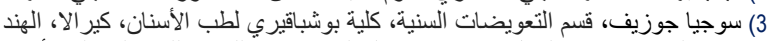

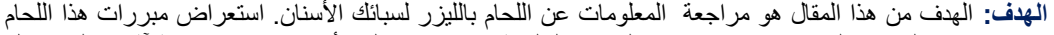

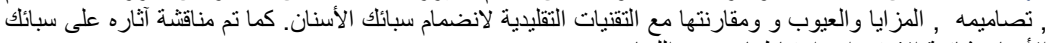

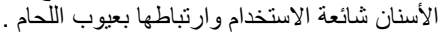

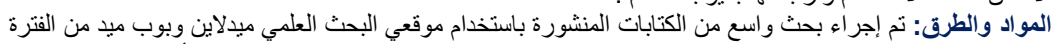

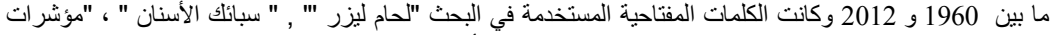

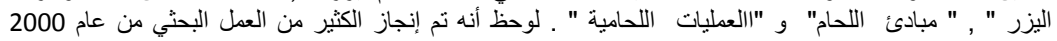

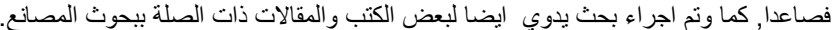

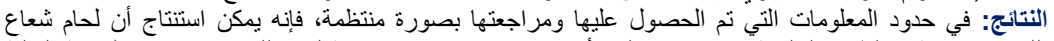

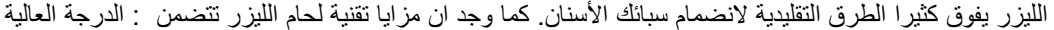

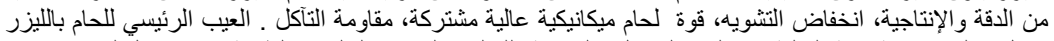

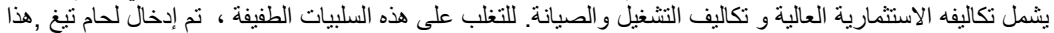

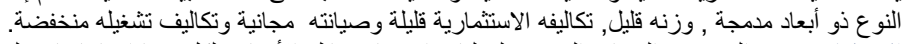

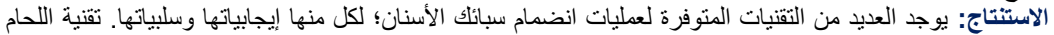

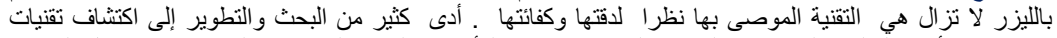

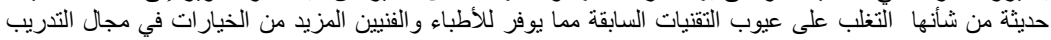
الكافي و الخبرة العملية .

Copyright (C) 2014. LDJ. This is an open access article distributed under the Creative Commons Attribution 3.0 License, which permits unrestricted use, distribution, and reproduction in any medium, provided the original work is properly cited. 
INTRODUCTION:

L aser technology isone such technological advancement that has replaced the conventional clinical, surgical and technical procedures. Due to its high precision, accuracy and productivity, it has been effectively employed in many industrial fields ${ }^{1}$. The first laser device was invented by Theodre Maimann in 1960, and its first laboratory test was conducted by Gordon and Smith in $1970^{2}$.The various methods of joining dental alloys or metal structures include soldering, resistance (spot) welding, plasma (torch) welding, laser welding and single pulse tungsten inert gas welding. Despite the limitations of soldering, soldering of gold has proved to be highly successful ${ }^{3}$. However, soldering of nonprecious alloy has resulted in high failure rates in vivo ${ }^{3}$. With the increased use of titanium and the invention of compact, high power pulsed $\mathrm{Nd}$ :YAG laser units, research in the field of laser welding has increased. A broad search of the published literature was performed using Medline and pub med from 1960 to 2012. The key words used for the search were 'laser welding', 'dental alloys', 'laser parameters', 'welding principle' and 'welding procedure'. It was observed that much of the research work was done from the year 2000 onwards. A hand search of textbooks, relevant articles, and manufacturers' literature was also conducted. Hence, this paper reviews the rationale, principle of laser welding, procedure and parameters involved and its influence on tested alloys.

\section{RATIONALE OF LASER WELDING:}

The commonest conventional method of connecting dental alloys was soldering (brazing) which is still being practiced despite its known limitations. Soldering is relatively complex and time-consuming. Itrequires multiple preparation steps to modify or repair prosthesis, with each step a source of distortion or misfit ${ }^{1}$. It also requires a third low fusing alloy (solder) with a different chemical composition and a melting point lower than the parent alloy. These solders contain cadmium, gallium, nickel and chromium whichconstantlydissolve in the oral environment leading to oral toxicity and settle in organs like the kidney and liver posing serious health problems. As a result of corrosion, the prosthesis becomes more brittle with time. Stress corrosion may lead to reduced mechanical stability of the soldered joints. Poor color matching of the solder with the area to be soldered also exists. There is an increased chance of burning the denture base resin due to the fire and gas involved in the procedure resulting in color damage. Due to the oxidizing property of titanium, soldering titanium is relatively impossible. Finally soldering is highly technique sensitive. On the contrary, the advantages of laser beam welding outwitted the conventional procedures in that there was less distortion involved due to the narrow heat affected zone (HAZ) producing narrow welds with controlled bead size ${ }^{2}$, faster welding with high productivity, minimum contamination with oxide free and polished seams and high mechanical strength of the welded seams. Since all the welding is done directly on the master cast, the amount of time consumed is considerably reduced. Prosthesis distortion is also reduced as it does not involve multiple preparation steps resulting in a precise fit. No additional metal or solder is required. Weld is with the parent metal (self-welding) thereby eliminating any galvanic effect. The joint formed is corrosion resistant. Welding very close to acrylic resin or ceramic is also possible with no physical cracking or color damage. Laser welding is conducive to all metals particularly titaniumalloys. Laser welding joint has a homogenous structure with a high mechanical strength, consistent with that of the parent alloy. Welding titanium occurs in an argon gas environment providing a biocompatible and corrosion free prosthesis. The weld affected area is of limited range of approximately $0.25-2 \mathrm{~mm}$, hence the risk of warping is eliminated. Solmi et $\mathrm{al}^{4}$ in their study on the interaction of fibroblast with soldered and welded joints concluded a superior fibroblast biocompatibility with welded joints. Laser weld jointhave been found to be $100 \%$ hypoallergenic with the weld remaining non-reactive and insoluble in oral fluids.

\section{PRINCIPLE OF LASER WELDING:}

The energy from a laser beam consists of a spot of stimulated and amplified 'light' radiation based on the reflection or mirror principle. This 'light' generated from the laser head is responsible for melting the alloy. The 'heart' of the laser welder is the laser head which consists of a laser lamp (similar to flashlight of the camera) and a laser crystal (Nd: YAG crystal) that are arranged parallel to each other. The active medium hosts the garnet crystals that are stable. For laser beam emission, the garnet 
crystals are stimulated with neodymium or yttrium. The ends of the crystal are silvered to function as mirrors internally which serve as the optical resonator responsible for amplification of the beam. A tiny hole exists at one of the end mirrors through which the laser beam emerges. A laser impulse is initiated by pushing the foot switch which is connected to the power supply and serves as the external energy source. This in turn causes the laser lamp to flash. The laser lamp converts 'electrical' energy stored in the capacitor's bank into 'light' energy. The optical resonator brings the 'concentrated light energy' to the delivery unit of the laser machine where it is focused to the object to be welded with a defined energy. The control system controls parameters such as power, pulse duration, pulse energy, pulse repetition rate, pulse shape, focal spot size, and the welding atmosphere in the welding chamber. The optical energy focused onto the work piece is converted to heat energy, Figure 1. The temperature generated can be optimized for effective welding.

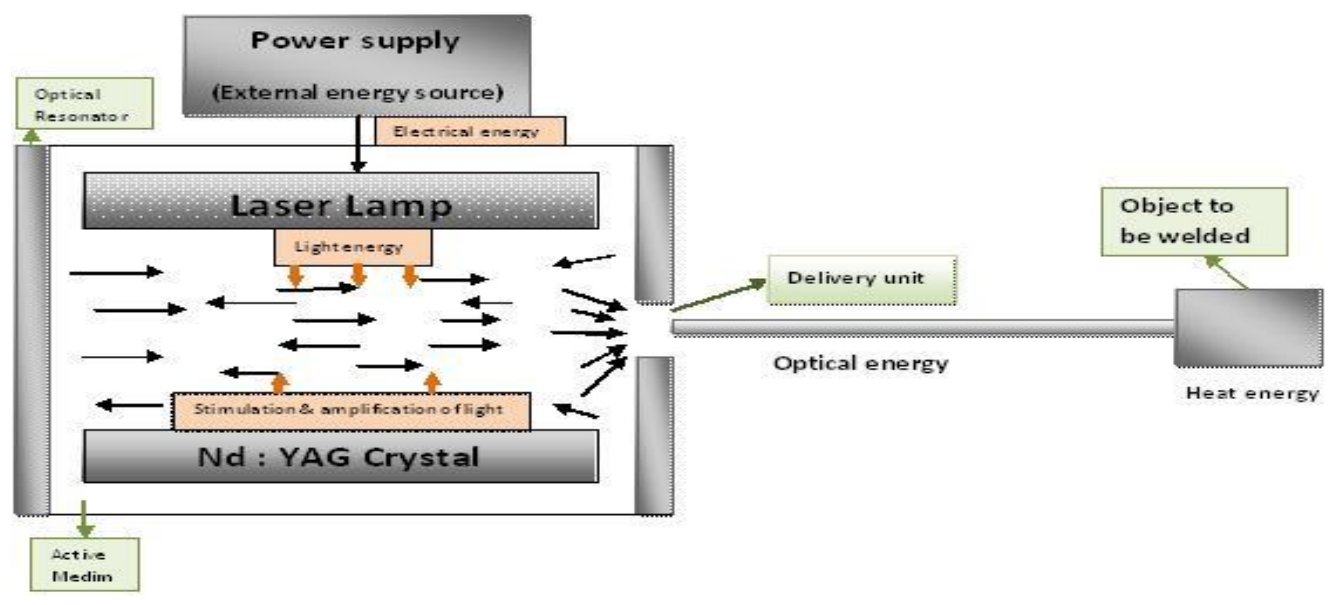

Fig: 1. Laser beam device

Since most of the laser output is in the form of heat, a cooling system is required. Gas and liquid cooling systems are available, of which gas is preferred.

\section{LASER PARAMETERS:}

A combination of parameters are required for a successful and efficient weld: laser peak power $(\mathrm{P})$; pulseduration; pulse energy; pulse repetition rate; pulse shape; focal spot size and the welding atmosphere in the welding chamber; the type of alloy used (precious, semi-precious, or nonprecious); metal preparation; the gap between two parts; design and composition of the filler; surface characteristics of the material and the operator's skill ${ }^{5}$. Appropriate selection of these parameters results in the finest and deepest welds $^{6-9}$. Laser peak power $(\mathrm{P})-$ refers to the density of energy delivered per unit of time $(\mathrm{J} / \mathrm{s}$ or Watts). Increasing the peak power overcomes thermal diffusivity and reflectivity of the material with the increased possibility of liquid material projection. Hence to avoid defects such as cracks and porosities, the peak power $(\mathrm{P})$ has to be controlled depending upon the alloy. Pulse duration is the length of time of a pulse. According to each metal's thermo physical properties, it can be set to a range of $0.5-20 \mathrm{~ms}$. The pulse duration must be reduced in alloys with good thermal conductivity (e.g. gold alloys). An increase in pulse duration can result in heat diffusion phenomena, to distortion of artifacts even to the extent of vaporization of alloying elements. Pulse energy ( $\mathrm{J}$ or W/s) is the relation of power $(\mathrm{kW})$ to pulse duration $\mathrm{t}(\mathrm{ms})$. To limit welding defects, the pulse energy must be optimized in relation with that of power and pulse duration. To obtain a deep and satisfactory weld, and increase in energy output is required ${ }^{10}$. But when the peak power is considerably increased, an increased risk of welding defects like porosities and surface voids have been noted $^{11}$. On the contrary, when power is decreased and pulse duration increased, the metal is subjected to excessive heat transfer resulting in a reduced penetration and an 
incomplete weld joint ${ }^{1}$. Pulse repetition rate $(\mathrm{Hz})$ is the number of pulses delivered per second. A pulse frequency of $1 \mathrm{~Hz}$ to $5 \mathrm{~Hz}$ produces controlled welding using a multi-spot process. According to Bertrand $^{7}$ an optimum pulse frequency of 1 to $2 \mathrm{~Hz}$ is recommended for titanium alloys. Pulse shape allows the control of the pulse peak power and pulse duration. Different pulse shapes are available, Figure 2. Appropriate selection of the pulse shape affects the final quality and mechanical property of the material $^{7,12 \text {, and } 13}$.

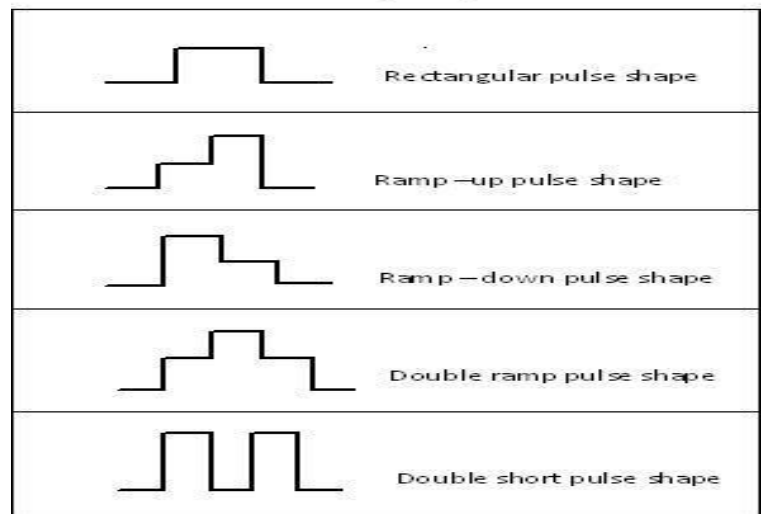

Fig: 2. Pulse shape designs1

Focal spot size determines the diameter of the laser beam applied to the surface of the material. The focal spot size is influenced by fluence, which is defined as the pulse energy over the irradiated surface. For prosthetic welding procedures, a focal spot size of $0.4-0.6 \mathrm{~mm}$ is optimum7. The position of the focal point in relation to the surface of the metal also matters. According to Cicila et al14 a focal spot located at the surface of the metal provides best weld stability unlike a position above or below the focalized point. Welding atmosphere in the welding chamber- a contaminant free welding atmosphere in the laser chamber is particularly important in the welding of titanium and its alloys as it is highly sensitive in the presence of hydrogen, nitrogen, and oxygen 15,16 . A blue spot indicates oxidation in the joint $(\mathrm{TiO} 2)$ and a yellow spot indicates the presence of nitrogen (TiN). Hence an argon atmosphere is essential during laser welding to prevent oxidation and porosities 15. The surface of the metal appears shiny gray when the flow of argon is correct, approximately 2 bars flow pressure.

\section{PROCEDURAL GUIDELINES:}

Laser welding is a technique which is highly dependent on operator's dexterity. His ability and knowledge of the effects of the various settings of the control panel will result in a more dependable and stronger weld ${ }^{17-19}$. The composition of the metal before laser welding must be identified. Precious alloys with concentration of zinc $\geq 2 \%$ or silver $\geq 20 \%$ and non-precious alloys with reduced amounts of boron, silicon or carbon have proved to have poor weld ability ${ }^{5}$. To reduce war page, 'I' or ' $\mathrm{X}$ ' shape joint surfaces are prepared with discs under water spray. For alloys with good weld ability and for reduced weld gaps the 'I' shape is preferred. For large weld gaps where a filler would be required the ' $\mathrm{X}$ ' shape is preferred, Figure 3. The joint surfaces are then prepared as parallel to each other as possible, sandblasted with alumina powder $(0.5 \mu \mathrm{m})$, cleaned with acetone or alcohol and hot-air dried before welding. The framework is then placed on the master cast which is in turn stabilized on an adjustable platform. The welding parameters are then adjusted according to the metal's composition, thickness and thermo physical properties. Welding is initiated at three spots followed by overlaps to ensure complete welding. Figure 4.

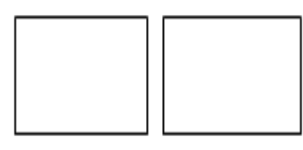

I' shape joint configuration

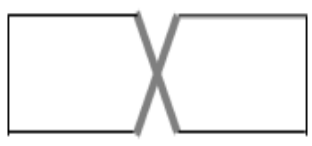

x'stape joint configuration
Fig: 3. 'I' and ' $\mathrm{X}$ ' shape configurations1
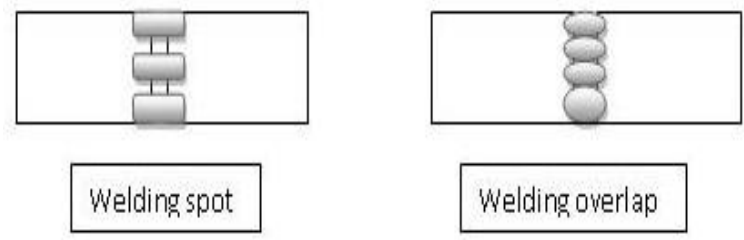

Fig: 4. Welding spot and welding overlap ${ }^{1}$

\section{WELDING DEFECTS:}

Gas porosities range from small bubbles to macro cavities. Low welding speeds and low pulse rate lead to a rapid solidification process ${ }^{15}$. Contamination porosity occurs when the welding zone is contaminated with air, grease or dampness. Pulse shape significantly influences porosity formation ${ }^{20}$. Kakimoto et $\mathrm{al}^{21}$ observed more porosity in $\mathrm{CoCr}$ alloy than commercially pure titanium( $\mathrm{cpTi}$ ) on using the rectangular pulse shape. In spite of the immediate cooling system, hot cracks are formed due to rapid and localized heat generation causing a change in the microstructure of the alloy and coarse hardening $^{5}$. As a result, the material undergoes 
shrinkage and contracts inside the fusion zone on cooling inducing tensile stress and crack formation. These cracks frequently originate from pores. Hot cracks usually occur as a localized area inside the weld nugget or between the HAZ and the nugget zone and affect joint durability $^{5,22}$. Cold cracks are thin with no oxides on their surface and occur at low temperature. They can be caused due to an incomplete weld or poor damping of the pieces to be joined. Cold cracks are causative factors for brittleness and corrosion. The formation of cracks can be prevented by the use of a filler to obtain a plain surface, preheat treatment of the material and post welding treatment of the weld. Also a control over of the laser welding process, microstructure and chemical composition of the welded alloy and the welding atmosphere are advised.

\section{EFFECTS OF LASER WELDING ON DENTAL ALLOYS:}

Several studies have been conducted by various researchers on the effect of laser welding on the alloys that are used in dentistry. The study parameters included, penetration depth, mechanical properties of the metals, weld strength, thermal conductivity, weldability and corrosion resistance. Due to their high reflectivity to Nd-YAG wavelength, gold alloys have excellent thermal conductivity but poor thermal absorption. Hence a high energy output is required to prevent overheating and heat diffusion $^{23}$. Watanabe et al $^{9}$ suggested the use of a black marker to aid in decreasing the reflectivity before welding. They also suggested an increased current and decreased spot diameter for better penetration depth ${ }^{24}$. Fornaini et $\mathrm{al}^{25}$ noticed improved mechanical properties when the laser welding gold alloys were subjected to softening heat treatment after laser welding followed by aging heat treatment at high or intra oral temperatures. On the other hand, Watanabe et $\mathrm{al}^{26,27}$ observed an increase in weld strength and \% elongation after age hardening heat treatments than softening heat treatments in gold alloys, Ag, Pd based alloys and $\mathrm{CoCr}$ alloys. $\mathrm{He}$ also observed that double welded gold alloy specimen's demonstrated increased joint strength than single welded specimens after heat treatment. Watanabe et $\mathrm{al}^{27}$ in their study on the influence of argon shielding on laser welding dental alloys noticed that failure loads of laser welded gold alloys were not influenced by argon shielding. Watanable and $\mathrm{Baba}^{24}$ studied the effects of welding on penetration of laser into titanium and $\mathrm{Au} \& \mathrm{Ag}$ based alloys. They observed that an increased current and decreased spot diameter resulted in an increased penetration depth for $\mathrm{Ag}$ based alloys. Betrand et $\mathrm{al}^{28}$ in their study on the influence of pulse shape on weld defects suggested a slow cooling ramp or double ramp in controlling hot cracking and internal porosities in $\mathrm{Pd}$ based alloys. $\mathrm{NiCr}$ alloys and $\mathrm{CoCr}$ alloys have less reflectivity but lower thermal conductivity. Hence a low energy output, medium power rate with long pulse duration proves optimum to overcome poor thermal conductivity ${ }^{5,29}$. A higher level of carbon and boron is responsible for $\mathrm{NiCr}$ alloys' poor weldability ${ }^{5}$.Heat treatments improve mechanical properties and microstructure of welded $\mathrm{NiCr}$ and $\mathrm{CoCr}$ alloys ${ }^{30}$. Laser welding of $\mathrm{CoCr}$ alloys produced excellent weldability results ${ }^{5}$.with an approximately $2 \mathrm{~mm}$ maximum depth of welding obtained which is the amount of thickness required for components to be repaired ${ }^{5}$.Laser welded ' $\mathrm{X}$ ' and ' $\mathrm{I}$ ' shaped joints demonstrated an increased corrosion resistance due to its passivation ability ${ }^{31}$; but a shallow weld penetration was observed in these joints resulting in reduced tensile strength ${ }^{31}$. On the other hand a brazed joint significantly increased the tensile strength and reduced corrosion resistance. The major problem in welding titanium is their high sensitivity to oxidation or nitriding during heating. This hardens the titanium surface and weakens the joint resulting in brittle welds ${ }^{16,32}$. Two methods suitable for welding titanium are plasma welding and laser welding; of which laser welding is most preferred due to its low thermal alteration of work pieces ${ }^{33}$. The use of an argon or helium shielding atmosphere in the laser chamber eliminates these contaminants ${ }^{16}$ and results in better mechanical properties ${ }^{34}$. Finite element analysis of fixed distal extensions and fixed partial prosthetic designs revealed principal stresses about the welded joint which did not exceed the ultimate tensile strength of the welded joint. Hence it can be assumed that mechanical failure may not occur in biomechanical conditions of the oral cavity ${ }^{35}$.A high peak power with short pulse durations and reduced spot diameter resulted in better penetration depth ${ }^{24}$. This was attributed to the low thermal conductivity and high laser beam absorption of titanium alloy ${ }^{24}$. The use of a high peak power to obtain appropriate energy level can cause ejection of the material on the surface. 
To compensate for this, filler has to be used. More the laser weld pass with filler wire (1 or 2 weld overlapping), higher the flexural strength and fracture resistance of cantilevered titanium joints relative to the previous weld ${ }^{36}$. Iwasaki et $\mathrm{al}^{37}$ reported pre-welding to reduce the final distortion of both single and double welds. Double welded specimens demonstrated less distortion than single welded specimen $^{38}$. A rectangular pulse shape and pulse frequency of 1 to $2 \mathrm{~Hz}$ can be recommended for titanium alloys as optimum. But an increased pulse frequency caused more metal ejection and plasma on the surface of the metal increasing the oxygen contamination in the welded area ${ }^{7}$. Also optimal conditions of pulse duration 10 to 12 $\mathrm{ms}$, pulse energy level of 300 to $310 \mathrm{~V}$, laser output levels of $270 \mathrm{~A}$ to $300 \mathrm{~A}$ and reduced thickness of pieces to be joined ${ }^{8,39}$ resulted in better mechanical properties and increased joint strengths of welded titanium similar to nonwelded titanium ${ }^{39}$. Whenever fracture occurred, it was usually at the center of the weld ${ }^{39}$.

\section{DRAWBACKS OF LASER WELDING:}

The main drawback of laser welding includes its high investment, operating and maintenance costs. Due to its slow welding speeds (25 to 250 $\mathrm{mm} / \mathrm{min}$ ), puddles may occur at the fusion point. Laser welding is limited to depths of approximately $1.5 \mathrm{~mm}$ and additional energy only tends to create gas voids and undercuts in the work. Metals like magnesium tend to vaporize and produce severe surface voids. To overcome the minor drawbacks of laser welding, a pulsed micro electric arc welder which utilizes single pulses of tungsten gas was introduced. Unlike laser which applies 'light' energy, tungsten inert gas (TIG) applies 'electric' energy. It is designed with automatic argon gas coverage of the welding spot which is delivered directly through the hand piece. It involves reduced investment costs, very compact dimensions, low weight, maintenance free and low operating costs. TIG welding with argon shielding with filler wire produced strongest and fracture resistant joints ${ }^{37}$.

\section{CONCLUSIONS:}

A number of techniques are available for joining dental alloys; each having its own pros and cons. Laser welding still remains the recommended technique due to its precision. The reduced heat involved during the procedure decreases the amount of distortion. Continuing research and development are resulting in newer technologies that can overcome the drawbacks of previous techniques. These will provide clinicians and technicians more options in the realm of adequate training and operator expertise.

\section{REFERENCES:}

1) Caroline Bertrand, Angeline Poulon-Quintin. Proposals for optimization of Laser welding in Prosthetic Dentistry. Journal of Prosthodontics 2010; 19:69-76.

2) Gordon TE, Smith DL. Laser welding of prostheses: an initial report. Journal of Prosthetic Dentistry 1970;24:472-476.

3) Harvey Apothekar, Ichiro Nishimura, Carl Serratan. Laser welded vs. soldered non precious alloy dental bridges: a comparative study. Lasers in surgery and medicine 1984(4);2:207-13.

4) R. Solmi, D. Martini, M. Zanarini, "et al". Interactions of fibroblasts with soldered and laser welded joints. Biomaterials 2004;25(4):735-740.

5) C. Bertrand, Le Petitcorps, L. Albingre V. Dupius. Prosthodontics: the laser welding

6) technique applied to the non precious alloys procedure and results. British Dental Journal 2001;190:255-257.

7) Bertrand C, Le Petitcorps Y, Albingre L, "et al": Optimization of influent parameters for laser welding in dentistry. British Dental Journal 2004;196:413-18.

8) Bertrand C, Laplanche O, Rocca JP, "et al". Effect of the combination of different welding parameters on melting characteristics of grade 1 Titanium with a pulsed Nd:YAG laser. Lasers Medial Science. 2007;22:237-244.

9) Chai T, Chou CK. Mechanical properties of laser welded cast titanium joints under different conditions. Journal of Prosthetic Dentistry 1998;79:477-483.

10) Watanabe I, Baba N, Chang J, "et al". $\mathrm{Nd}$ :YAG penetration into cast titanium and gold alloy with different surface preparations. Journal of Oral Rehabilitation 2006;33:433-46.

11) Baba N, Watanabe I, Liu J, "et al". Mechanical strength of laser welded $\mathrm{CoCr}$ alloys. J Biomed Mater Res B Appl Biomater 2004;69B:121-124.

12) Matsunawa A, Kattayama $S$, Ikeda $H$, "et al". Effect of pulse shape on defect reduction in pulsed laser welding. ICAELO Proc 1992;547556.

13) Bertrand C, Laplanche O, Poulon-Quintin A. Investigation of the influence of $\mathrm{Nd}$ :YAG laser welding parameters on dental metallic alloys 
microstructure: a preliminary study. Proceedings of the First Meeting of the European Division of the World Federation for Laser Dentistry, Nice University, France, April 2007.

14) Bertrand $C$, Poulon-Quintin $A$. Influence of the Pulse- Shaping on the Weld Quality of a PdAg alloy. Abstracts of the 11th Meeting of the WFLD, China, July 2008.

15) Cicala E, Duffet G, Andrzejewski H, "et al". Hot cracking in Al-Mg-Si alloy laser welding operating parameters and their effects. Mat Sci Engineering A 2005;39:1-9.

16) Grevey D, Sallamand P , Cicala E, "et al". Gas protection optimization during the Nd:YAG laser welding. Optic Laser tech 2004;37:647651.

17) Donachie MJ Jr,:Ttitanium a technical guide (ed 2). Materials Park, OH, ASM International, 1984, 67-79.

18) Jean -Marc Meyer. Research Summary: reducing the variation in laser welding. British Dental Journal 2004;196:407.
19) Capello E, Previtali B. The influence of the operator skills, process parameters and materials on clad shape in repair using laser cladding by wire. J Mater Process Tech 2006;174:223-232.

20) Waddell JN, Payne AG, Swain MV. Physical and metallurgical considerations of failures of soldered bars in bar attachment systems for implant overdentures; a review of literature. Journal of Prosthetic Dentistry 2006;96:283287.

21) Haboudoua A, Peyera P, Vannes A, "et al". Reduction of porosity content generated during Nd:YAG laser welding Of A356 and AA50083 aluminum alloys. Mat Sci Engineering A 2003;363:40-52.

22) Kakimoto $K$, fujioka $S$, Inoue $T$, “et al". Porosity formation by laser welding in rectangular pulse shape. Journal of Dental Material 2005; 24:421-430.

23) Matsuda F, Ueyama T. Solidification crack susceptibility of laser weld metal in 0.2- 